Running Head: Competition and facilitation in compound conditioning

\title{
Competition and facilitation in compound conditioning
}

\author{
Gonzalo P. Urcelay \\ Department of Neuroscience, Psychology \& Behaviour. University of Leicester.
}

Corr. author: Gonzalo P. Urcelay

Department of Neuroscience, Psychology \& Behaviour

University of Leicester

Lancaster Rd. Leicester, LE1 7HA, UK

TEL: $\quad$ +44 (0116) 2297173

E-mail: g gpu1@le.ac.uk

Submitted: 11 December 2016, Revised: April 2017, Re-Revised, June 2017.

In press: Journal of Experimental Psychology: Animal Learning and Cognition

(C) 2017, American Psychological Association. This paper is not the copy of record and may not exactly replicate the final, authoritative version of the article. Please do not copy or cite without authors permission. The final article will be available, upon publication, via its DOI: $10.1037 / x a n 0000149$ 


\begin{abstract}
Despite the generality and theoretical relevance of cue competition phenomena such as blocking and overshadowing, recent findings suggest that these observations may be due to some degree of publication bias, and that we lack insight into the boundary conditions of these phenomena. The present commentary does not question the existence of cue competition phenomena. Rather, I review findings showing that three variables, namely 1) relative stimulus duration, 2) contingency, and 3) contiguity parametrically determine not only whether cue competition is observed, but also whether no cue interaction, or cue facilitation occur. I discuss theoretical interpretations and implications of these findings, which may provide illuminating insights into the generality and functional significance of the commonly cited 'principles of learning'.
\end{abstract}

Key Words: cue competition; cue facilitation; compound conditioning; Pavlovian conditioning; instrumental conditioning; overshadowing; potentiation; blocking; augmentation 


\section{Competition and facilitation in compound conditioning}

With a few exceptions, most associative theories of learning have been developed to explain deficits in learning and performance in the face of cue-outcome pairings. That is, phenomena such as cue competition have dominated theoretical debates and become a benchmark for all contemporary theories of learning. Cue competition refers to a family of phenomena in which the relationship between two events $(\mathrm{X}-\mathrm{O})^{1}$ is not readily evident as a change in behaviour (either not learned, or not expressed) because during training, other events (i.e., A) occurred along with $X$. The first example (and perhaps the simplest) is overshadowing, which refers to decrements in responding to $\mathrm{X}$ when it was trained in the presence of another (usually more salient) stimulus A (AX-O; Pavlov, 1927). The more salient stimulus $\mathrm{A}$ is thought to attenuate learning about (or at least expression of) the $\mathrm{X}-\mathrm{O}$ relationship. Blocking is another example of cue competition phenomena (Kamin, 1968). In a blocking experiment, the target stimulus $X$ (i.e., the stimulus that we are concerned with and hence is tested) is trained in the presence of another stimulus $\mathrm{A}$ which has already been trained as a predictor of $\mathrm{O}(\mathrm{A}-\mathrm{O}$ during a first phase, and AX-O during a second phase). In these two examples, behavioural control by $\mathrm{X}$ is constrained by the presence of a more salient (overshadowing) or previously trained (blocking) A. Two other examples of cue competition phenomena are overexpectation (Rescorla, 1970) and relative validity (Wagner, Logan, Haberlandt \& Price, 1968). In over expectation, X and A are trained separately as predictors of $\mathrm{O}(\mathrm{X}-\mathrm{O}$ and $\mathrm{A}-\mathrm{O})$ during phase 1 . During phase 2 , both stimuli are presented as a compound and followed by the $\mathrm{O}(\mathrm{AX}-\mathrm{O})$. Behavioural control to $\mathrm{X}$ decreases as a result of phase 2 pairings. Finally, in a relative validity experiment, $\mathrm{X}$ is embedded in a discrimination

333

${ }^{1}$ In this commentary, I use the letters $\mathrm{X}$ and $\mathrm{A}$ to refer to events that precede a (usually) biologically significant outcome, which I refer to as $\mathrm{O}$. In general, $\mathrm{X}$ is the target stimulus (i.e., the stimulus which is tested later) and $A$ is the event that interacts (competes or facilitates) for behavioural control by $X$, but in instrumental experiments $X$ is a response $(R)$. 
between $\mathrm{A}$ and $\mathrm{B}(\mathrm{AX}-\mathrm{O} / \mathrm{BX}-\mathrm{NoO})$ in the experimental condition, while in the control condition both compounds are reinforced $50 \%$ of the time. Despite $X$ being paired with $050 \%$ in both conditions, less behavioural control is observed by $\mathrm{X}$ in the experimental condition relative to the control, presumably because in the former, $\mathrm{X}$ is presented along a consistent $(\mathrm{A})$ predictor of $\mathrm{O}$, which competes with $\mathrm{X}$ decreasing its behavioural control. In all these cue competition situations, $\mathrm{X}$ acquires less behavioural control as a result of being trained along another predictor of $O$.

Cue competition phenomena (i.e., overshadowing) were first observed by Pavlov (1927), but it was only after the observation of blocking (Kamin, 1968), relative validity (Wagner et al., 1968), and overexpectation (Rescorla, 1970) that theories of learning began to be devised with these phenomena in mind (Mackintosh, 1975; Miller \& Matzel, 1988; Pearce \& Hall, 1980; Rescorla \& Wagner, 1972; Wagner, 1981). Cue competition effects have been observed in both appetitively and aversively motivated tasks, and across a wide range of invertebrate species including planaria (Prados et al., 2013), snails (Acebes et al., 2009), and honeybees (Couvillon \& Bitterman, 1989), as well as vertebrates such as rodents (Kamin 1968), pigeons (Leyland \& Mackintosh, 1978), non-human primates (Waelti, Dickinson \& Schultz, 2001), and humans (Dickinson, Shanks \& Evenden, 1984). Thus, there are grounds to claim that, since their discovery, these effects have been observed across a wide range of tasks and species.

Despite the generality and theoretical importance of cue competition phenomena, a recent report by Maes et al. (2016) documented 15 failures to observe blocking in rats and mice out of 15 attempts. These carefully controlled experiments were run in different laboratories (KU Leuven, UCLA) and using stimuli of different sensory modalities (visual, auditory), motivational systems (appetitive, aversive), and species (rats, mice). The authors did not dispute that blocking exists; they instead suggested that we lack insight into the boundary conditions for it to occur, and that many of these boundary conditions need to be fulfilled in order to find blocking. Their argument, in other words, assumes a continuum along which "blocking" and "no blocking" are extremes, and we need to specify the relevant variables that determine either observation. In this commentary, I argue that cue competition phenomena should be seen as the extreme of a continuum between competition and 
facilitation, with a large zone in which neither is observed. By facilitation, I mean instances in which more behavioural control is observed after compound training with a more salient stimulus $\mathrm{A}$ (potentiation; Palmerino, Rusiniak \& Garcia, 1980) or a previously trained stimulus A (augmentation; Batsell \& Batson, 1999). The objective, then, is to define which variables determine whether (all other circumstances being equal) competition, no interaction, or facilitation between stimuli are to be observed. In the next section, I discuss three such variables which have been found critical in determining these outcomes. These variable are: 1) relative stimulus duration, 2) contingency, and 3) contiguity. This commentary is not meant to be a comprehensive review of the literature, and not all experimental findings fit entirely with these three variables, but the main objective is to highlight that different outcomes can be observed in designs which are empirically (and theoretically) thought to only lead to cue competition. In addition, I later discuss other variables (salience, number of trials, and mode of presentation [simultaneous vs sequential]) which have been observed to influence competition and facilitation after compound training, although I believe that the empirical findings regarding these variables are less conclusive.

\section{Variations in relative stimulus duration.}

It is well known that the duration of $X$ (among other variables) determines the amount of conditioned responding to $\mathrm{X}$ after $\mathrm{X}-\mathrm{O}$ pairings. In general, there is an inverted $\mathrm{U}$ shaped relationship between stimulus duration and behavioural control. Too short of an exposure (i.e., a small fraction of a second) does not lead to much behavioural control, perhaps because the organism does not have enough time to perceive the stimulus. Beyond such short durations, short stimuli (typically a few seconds) exert better behavioural control than long stimuli (e.g., minutes), an effect which is observed in many different preparations and species (see Rescorla, 1988; Figure 1). This phenomenon has been called the CS-duration effect. However, for a number of decades now, it has been clear that it is not the absolute duration of $\mathrm{X}$ alone what determines the success of conditioning, but rather the duration of $\mathrm{X}$ relative to the interval between trials (i.e., the inter-trial interval [ITI]; e.g., Gibbon, Baldock, Locurto, Gold \& Terrace, 1977). In other words, when X is short and the ITI long, strong 
behavioural control is observed. Thus, one can manipulate the duration of $\mathrm{X}$ and maintain the ITI constant, or one can keep the duration of $\mathrm{X}$ constant and manipulate the duration of the ITI and obtain similar effects. Whilst these two manipulations have predictable effects on conditioning with a single stimulus $X$, I review studies suggesting that the effect can be the opposite when training involves $A X$ O pairings.

One of the first studies to manipulate the duration of stimuli whilst training a compound AX-O was conducted by Westbrook and colleagues (Westbrook, Homewood, Horn, \& Clarke, 1983). In their Experiment 2, 4 groups of rats were used. Two groups of rats drank water whilst they were presented with the smell of cineole (X-O pairings). The duration of exposure was 2 or 15 mins. Two additional groups were exposed to a compound consisting of cineole plus quinine-flavoured water (AX-O pairings) with similar durations as the elemental groups. After flavour exposure, all groups received an injection of lithium chloride (which induced internal malaise). All groups were tested three days later by having them drink water whilst they smelled cineole. The two groups that were trained with cineole alone showed the expected pattern - short exposure resulted in stronger behavioural control (i.e., less water consumed) than longer exposure. However, the groups that were trained with the compound showed the opposite pattern. That is, when stimuli were short, overshadowing was observed. However, when cues were of long duration, the presence of quinine facilitated behavioural control by cineole at test. In other words, with long duration cues, overshadowing reversed into potentiation.

The generality of these findings was confirmed by three studies run in a different laboratory, and in a different preparation such as fear conditioning (Sissons, Urcelay \& Miller, 2009; Urushihara, Stout, \& Miller, 2004; Urushihara \& Miller, 2007). I here describe the report by Sissons and colleagues because it included three different durations of stimuli (rather than 2, which was the case in the reports by Urushihara et al.). In the report by Sissons and colleagues, 6 groups of rats received 4 trials of either a clicker alone followed by a mild footshock (X-O), or a tone-clicker compound followed by a mild footshock (AX-O). The duration of the cues was 5,25 , or 125 seconds, and the session length 20 mins. All groups were tested a few days later with the clicker alone (X). The main finding was that, with short duration stimuli (5s), robust overshadowing was observed. However, when cues 
were longer (125s), potentiation was observed. That is, more responding was observed to the long duration clicker $\mathrm{X}$ when it was trained as part of the compound $\mathrm{AX}$, than when it was trained alone. In Experiment 3 of that report, the authors replicated these results but in a sensory pre-conditioning preparation (Brodgen, 1939), in which a neutral stimulus (i.e., a white noise) was used as O during training, and later made biologically significant by pairing it with a footshock. In fact, Experiment 3 saw overshadowing with short stimuli, no effect with intermediate stimuli (25 s), and potentiation with long stimuli. Urushihara and colleagues (Urushihara et al., 2004; Urushihara \& Miller, 2007) also observed the reversal of overshadowing into potentiation. Taken together, these three studies conducted in fear conditioning replicate the results of Westbrook and colleagues (1983). It is important to emphasize that it is the relative stimulus duration, rather than the absolute duration, what determines the reversal of competition into facilitation. Early studies (indeed, Kamin's 1968 original experiments documenting blocking) have observed competition with long duration CSs (i.e., 3 mins) but in those experiments, 4 trials were administered in a 2 hour session, so the duration of the CS relative to the ITI was short, and hence competition is expected to be observed, as it was.

As mentioned above, the relative duration can be altered by changing the duration of the $\mathrm{X}$, or by altering the duration of the ITI. Downward changes in ITI are generally referred to as massed training, and result in less behavioural control than spaced training trials. At issue here is whether overshadowing wanes (or even turns into facilitation) when the duration of $\mathrm{X}$ is constant, but trials are massed (that is, the ITI is short). This is what Stout, Chang, and Miller (2003) set out to test in their study. In their Experiment 1, rats received pairings of either a 25-s clicker alone (X) or as a compound with a louder tone (AX; always followed by footshock). These two conditions were orthogonally assigned to massed training (40-s ITI) or spaced training (960-s ITI). With long ITIs, compound training resulted in less behavioural control - that is overshadowing (similar to the short cues described above). When trials were massed, the opposite was observed, that is, overshadowing reverted into potentiation. Sissons and Miller (2009) tested whether another cue competition phenomenon, overexpectation, would also revert into facilitation when trials were massed during training. They found overexpectation when trials were spaced, but the opposite (i.e., cue facilitation) 
after overexpectation training with massed trials. Similar findings have been observed with human participants in a blocking design. Beesley and Shanks (2012) used a contextual cuing of visual search task (which can be considered a task in which trials are massed, given that trial duration tends to be longer than the ITI) to investigate blocking and found augmentation instead of blocking.

In summary, the studies reviewed above suggest that cue competition is more likely to occur when trials are spaced and stimuli short than when trials are massed and stimuli long. Variations in this relationship, either by lengthening stimuli, or by shrinking ITIs, show a shift from cue competition to cue facilitation. The effects reported have been observed in different preparations (flavour aversion, fear conditioning, and cuing of visual search) and different cue competition phenomena (overshadowing, blocking and overexpectation). Thus, when other conditions are kept constant, variations in the relative duration of cues can result in cue competition or cue facilitation.

\section{Variations in contingency.}

The study of associative learning took a paradigmatic shift in the 60s when students of learning concluded that, for behavioural control to be observed, $\mathrm{X}$ has to provide novel predictive information about the occurrence of $\mathrm{O}$. One demonstration that supports this assertion involves variations in the probability that $O$ occurs in the presence of $X$, relative to the probability that it occurs in its absence. At issue was whether or not rats and other animals were sensitive to variations in these probabilities. This is what Rescorla set to test in a classic experiment (1968). Briefly, he used rats in a fear conditioning preparation in which all rats received X-O pairings (tone-shock); however, different groups experienced different frequencies of $O$ presentations in the absence of $X$, and of $X$ in the absence of $O$. In other words, across groups the likelihood of $O$ in the absence of $X$ (or vice versa) was varied. Rats showed a high sensitivity to these changes in contingency, as humans do (Allan, 1980; Shanks, 1987). As Rescorla showed, variations in X-O contingency can be achieved by presenting either $\mathrm{X}$ or $\mathrm{O}$ alone. $\mathrm{X}$ (or $\mathrm{O}$ ) alone exposure can be presented before, concurrently (as Rescorla did), or after $\mathrm{X}-\mathrm{O}$ pairings, resulting in a $2(\mathrm{X}$ or $\mathrm{O}) \times 3$ (before, during or after) matrix (see 
Figure 1). In the remainder of this section, I review data suggesting that overshadowing reverses into facilitation in 5 out of the 6 cells in the matrix. I start with $X$ alone presentations.

Presentations of $\mathrm{X}$ alone before $\mathrm{X}-\mathrm{O}$ pairings produce a retardation in the acquisition of behavioural control that is referred to as latent inhibition (Lubow \& Moore, 1959). Presentations of $X$ alone interspersed with X-O pairings lead to a decrement known as partial reinforcement (e.g., Pavlov, 1927; Wagner, Siegel, Thomas, \& Ellison, 1964). Notably, both of these detrimental effects on conditioning have been shown to attenuate overshadowing, and instead lead to facilitation. Blaisdell and colleagues (Blaisdell, Bristol, Gunther, \& Miller, 1998) were first to document such phenomenon. They trained 4 groups of rats in a fear conditioning preparation. During phase 1, two groups received non-reinforced exposure to $\mathrm{X}$ (i.e., latent inhibition treatment), and two groups received equal exposure to an irrelevant control stimulus Y. During phase 2, these groups were orthogonally assigned to receive elemental $(\mathrm{X}-\mathrm{O})$ or overshadowing $(\mathrm{AX}-\mathrm{O})$ training. Groups that received latent inhibition alone, or overshadowing alone, showed less conditioned responding relative to the control group in a test conducted days later. However, the group that experienced both latent inhibition treatment and overshadowing treatment responded more at test than those groups that received either treatment alone, suggesting that overshadowing is not observed when the contingency is degraded by pre-exposing X. Using flavour aversion learning, Loy and Hall (2002) reported a similar finding in their experiment 5 . That is, two groups received preexposure to $\mathrm{NaCl}(\mathrm{X})$, and two groups did not. These groups then received overshadowing (AX-O), or unpaired (i.e., AX and $\mathrm{O}$ given a day apart) training. Critically, the group that experienced both pre-exposure $X$ and overshadowing (AX-O) training responded more to $\mathrm{X}$ during test than the group that received overshadowing training alone, thus supporting the idea that pre-exposure to $\mathrm{X}$ attenuates overshadowing (note that there was no $\mathrm{X}$ O elemental training group in this experiment, but instead an unpaired control). Although replication of these results has not been successful (Nagaishi \& Nakajima, 2008; Nakajima \& Nagaishi, 2005), they suggest that under some conditions, pre-exposure to $\mathrm{X}$ can attenuate overshadowing and reverse it into potentiation. 
One reason why CS pre-exposure may not always attenuate overshadowing may hinge on the phasic nature of these treatments. When treatments (such as $\mathrm{X}$ alone exposure) are given before (or after) X-O training, recency and primacy influence which information is dominant at the time of test (Lipatova, Wheeler, Vadillo \& Miller, 2006; Wheeler, Stout \& Miller, 2004). In addition, interference (Vadillo, Castro, Matute \& Wasserman, 2008) obscures the fundamental point highlighted here which is the manipulation of overall (i.e., global) contingency interacting with cue competition. This also applies to the blocking phenomenon, in which A-O pairings are administered either before or after AXO pairings. As observed by Vadillo and colleagues (Vadillo et al., 2008) when CD-O pairings were followed by training of an irrelevant cue G-O (i.e., a control for backward blocking) ratings to C and D decreased (relative to a control), suggesting that retroactive interference contributed to the observation of backward blocking (and presumably proactive interference contributes to the observation of forward blocking). Perhaps a fairer test of the notion that decreased contingency attenuates cue competition is achieved by interspersing $X$ (or $A X)$ alone with $A X-O$ training, rather than administering all the $\mathrm{X}$ alone trials before AX-O training. This is what Urushihara \& Miller (2007) did. In their Experiment 1, Urushihara and Miller used six groups of rats in a fear conditioning preparation. Three groups experienced elemental X-O training, and three groups received compound training AX-O (i.e., overshadowing treatment). One group from each condition was trained with short stimuli, and one with long stimuli (thus further assessing the results reported by Urushihara et al., 2004, see above). The third group from each condition received partial reinforcement with elemental or compound training. As previously observed by Urushihara et al (2004), long duration of compound cues during training led to facilitation rather than overshadowing. Similarly, conducting overshadowing training whilst also giving partial reinforcement of the compound (interspersed AX/ AX-O trials) resulted in facilitated responding to $X$ at test. Thus, partial reinforcement attenuated overshadowing and lead to facilitated learning. Whether compound training (AX-O) followed by $\mathrm{X}$ alone exposure after the pairings (i.e., extinction; see Figure 1) also leads to facilitation is an open question, but the present results suggest that non-reinforced presentations of $X$ (or $A X)$ either before or during conditioning can attenuate overshadowing. I should note that Neely and Wagner (1974) reported an experiment in 
which blocking was observed with the use of $25 \%$ partial reinforcement during Phase 2 , a result at odds with the current analysis. However, they did not observe sensitivity (in responding to A) to variations in contingency between the blocking cue $\mathrm{A}$ and $\mathrm{O}$ ( $100 \%$ vs $25 \%$ contingency) so it is difficult to assess the sensitivity of their experiment to observe variations in blocking, as would be expected based on the current analysis.

Variations in contingency are easily achieved in instrumental scenarios with the use of different ratios of reinforcement. For example, Reed, Schachtman \& Hall (1988) trained in Experiment 1 different groups of rats to press a lever $(R)$ for pellet reinforcement. Two groups were trained with a variable ratio (VR) 10 (so that, on average, one pellet was presented every 10 responses), whilst two additional groups were trained with a VR30 (on average, one pellet every 30 responses - a much lower response-reinforcer contingency). These groups were orthogonally divided so that the reinforcer could be signaled or not with a stimulus A. A comparison of the two groups trained with the VR10 suggested no effect of the signal A, although a tendency towards an increase in responding was observed (no overshadowing, if anything the opposite). In the groups which experienced a much lower response-reinforcer contingency (VR30) responding was much higher, as expected (Ferster \& Skinner, 1957). In these groups, the signal for reinforcement A robustly potentiated responding, consistent with the idea that lower response-reinforcer contingency led to potentiation rather than competition (which was the original aim of their experiment).

As mentioned above, an alternative way to alter the global $\mathrm{X}-\mathrm{O}$ contingency is to present $\mathrm{O}$ alone, as this would objectively increase the probability of $O$ in the absence of $X$. As seen in the bottom row of Figure 1, O alone presentations can be administered before, during, or after X-O pairings. The question is whether $\mathrm{O}$ alone presentations attenuate cue competition phenomena such as overshadowing. Urushihara and Miller (2006) used a sensory preconditioning preparation in which a light served as $\mathrm{O}$ during training, and was later paired with a mild footshock. They tested whether $O$ alone before or after $\mathrm{X}-\mathrm{O}$ pairings attenuates behavioural control by $\mathrm{X}$, and indeed this is what they observed. Consistent with an interpretation in terms of decreased $\mathrm{X}-\mathrm{O}$ contingency achieved by $\mathrm{O}$ alone presentations, $\mathrm{X}$ elicited less responding when $\mathrm{O}$ was presented alone either before or after $\mathrm{X}$ - 
O pairings. However, this was not the case when they trained AX-O, that is, when they administered compound training. Under these circumstances, $\mathrm{O}$ alone before or after $\mathrm{AX}-\mathrm{O}$ pairings increased responding to $\mathrm{X}$ at test, which is consistent with the view that overshadowing reverses into facilitation when the contingency is altered by adding appreciable $\mathrm{O}$ alone presentations.

For somewhat different reasons, Maier, Jackson, and Tomie (1987) also observed a reversal of overshadowing into facilitation with prior exposures to $O$. In their Experiment 1, rats received escapable shocks, inescapable shocks, or no shocks in phase 1 (the inescapable shock is equivalent to $O$ pre-exposure). During the second phase, each of these three groups were divided into two groups that experienced shuttlebox avoidance training with or without a feedback signal. In subjects that experienced no shocks in phase 1, the feedback signal after avoidance decreased avoidance behaviour, a result equivalent to overshadowing of the avoidance response by the signal. However, when subjects had previously experienced inescapable shocks (O pre-exposure) and experienced the feedback signal during training, they performed better than subjects which did not experience inescapable shocks. In other words, inescapable shocks reversed the overshadowing deficit. Urcelay and Miller (2006) conducted an experiment in which rats received $O$ alone interspersed with the AX-O pairings (degraded contingency; see Figure 1). They observed (in first order conditioning and in sensory preconditioning) that degrading the AX-O contingency by $\mathrm{O}$ alone exposure attenuated the overshadowing deficit, in fact turning it into facilitated responding to $X$ at test (relative to an overshadowing group which did not receive degraded contingency).

In summary, I have reviewed evidence that, out of six ways of decreasing the $\mathrm{X}-\mathrm{O}$ (or AX-O) contingency by presenting $\mathrm{X}$ (or $\mathrm{AX}$ ) or $\mathrm{O}$ either before, during or after $\mathrm{AX}-\mathrm{O}$ conditioning (see Figure 1), five of them (except extinction) seem to attenuate cue competition phenomena and reverse it into potentiation. The results reported here are somewhat constrained to overshadowing in aversively motivated preparations, and not always found across labs and preparations. In addition, exposure of $X$ vs $A X$ alone may have different effects given that exposure to the $X$ alone can disrupt configural processing of the compound (see Theoretical implications). Yet, collectively, these results suggest that, when the contingency is objectively decreased by administrations or $X$ (or AX) or $O$ alone, a well- 
Competition and Facilitation 13

known cue competition phenomenon such as overshadowing may reverse into potentiation. An interesting challenge for future studies is to see whether these results also apply to other cue competition phenomena such as blocking, overexpectation, or relative validity. At least with overshadowing, the evidence seems to suggest that variations in contingency not only may reduce it, but sometimes lead to facilitation.

\section{Variations in contiguity.}

Contiguity, that is spatial and temporal closeness, is a variable that has long been known to have an effect on associative learning (see Boakes \& Costa, 2014, for a recent review). Decreasing contiguity between $\mathrm{X}-\mathrm{O}$ has always been observed to be detrimental when the onset asynchrony (i.e., the trace) is beyond a few hundred $\mathrm{ms}$. This is the case when $\mathrm{X}$ is a stimulus (Pavlovian learning), or when it is a response (instrumental learning). For example, Roberts (1930) trained rats to contact a pendulum to gain access to a feeding cage in which the rats had access to food. He trained 4 groups of rats, and varied the time $(0,5,10,30 \mathrm{~s})$ between contacting the pendulum and the opening of the door leading to the feeding cage. All groups learned to contact the pole, but those with a delay between the response $(\mathrm{R})$ and access to food $(\mathrm{O})$ took longer to learn, in a delay dependent manner. Similar delay dependent effects have been observed in Pavlovian fear conditioning (Kamin, 1961) and in humans pressing a button to produce visual stimulation in a computer monitor (Shanks \& Dickinson, 1991). Unfortunately, most researchers lost interest in contiguity after the observation of blocking (Kamin, 1968) and contingency manipulations (Rescorla, 1968) because these suggested that contiguity was not sufficient for learning to occur. Neither did good contiguity seem to be necessary, as flavour aversion learning could support traces between X and O of hours (e.g., Garcia, Erwin, \& Koelling, 1966). I here review evidence in rats and humans suggesting that contiguity manipulations can have a drastic effect in cue competition. This evidence, not only suggests that competition may not occur when contiguity is manipulated, but indeed that manipulations of contiguity can lead to facilitation of learning in a compound conditioning situation in which one would expect to observe competition. 
In Pavlovian fear conditioning, Urcelay and Miller (2009) manipulated the contiguity between X and $\mathrm{O}$ in elemental $(\mathrm{X}-\mathrm{O})$ and compound $(\mathrm{AX}-\mathrm{O})$ conditioning using rats as subjects. That is, presentation of the stimuli could be followed by a mild footshock immediately, 10 or $20 \mathrm{~s}$ later. The three groups that received X-O pairings showed a delay dependent effect - that is, conditioned responding was weaker when $X$ and $O$ were separated by 20 seconds than when there was no separation between the two (the 10-s separation group fell in between these two). However, in the compound training situation (AX), the opposite was observed. That is, with 0-s trace, $A X-O$ led to overshadowing of X. A 10-s trace showed no overshadowing nor facilitation, indeed an absence of interaction between cues. With a 20-s trace, increased responding to $\mathrm{X}$ was observed after $\mathrm{AX}-\mathrm{O}$; that is, facilitated learning (potentiation) was seen with the same cues that produced competition in the absence of a trace between $\mathrm{X}$ and $\mathrm{O}$. This interaction has been replicated in another fear conditioning experiment (Pezze, Marshall, \& Cassaday, 2016) and in a flavour aversion preparation by Batsell and colleagues (Batsell et al., 2012). In the flavour aversion experiments, two taste cues (denatonium and saccharide) were used as $\mathrm{X}$ and $\mathrm{A}$ and $\mathrm{LiCl}$-induced illness served as $\mathrm{O}$. Rats were exposed to either $\mathrm{X}$ or $\mathrm{AX}$ followed by $\mathrm{LiCl} 0,30,60$ or 120 mins later. In the absence of a trace, $\mathrm{AX}$ training led to overshadowing when $X(\operatorname{Exp} 1 \mathrm{a})$ or $\mathrm{A}(\operatorname{Exp} 1 \mathrm{~b})$ were tested later. However, with a 120-min trace, the same stimuli potentiated each other, irrespective of which stimulus was tested. With the intermediate traces, they sometimes observed no interaction between stimuli, thus replicating the results of Urcelay and Miller (2009). These results were recently replicated in humans. Cunha, Forehand and Angle (2015) exposed their participants to information about a new brand of cereal (X), and the fibre content it contained (O). New brands could be presented alone $(\mathrm{X})$, or in the presence of a well-known brand Kelloggs (AX training). Notably, fibre information $(\mathrm{O})$ could be presented immediately after the brands, or after a 5-s delay. Subjects were later asked to report their intention of buying the new brands $(\mathrm{X})$. When $O$ was presented immediately, the well-known brand overshadowed the new brand, and thus led to lower likelihood that people would try the new (test) brand (i.e., overshadowing). However, when the information $\mathrm{O}$ was delayed by $5 \mathrm{~s}$, subjects showed an increased likelihood to buy a new 
brand despite it being trained with the well-known brand - a facilitation effect similar to the ones observed in rodent studies.

The interaction between compound training and trace conditioning is not restricted to Pavlovian scenarios. Using pigeons in an instrumental scenario, Schachtman, Reed, and Hall (1987) trained their subjects to peck an illuminated disk to obtain food, which could be delivered $0.5 \mathrm{~s}$ after a reinforced peck $(R)$, or $3 \mathrm{~s}$ later. In addition, a brief signal A could be presented between peck $(R)$ and outcome $O$ presentation. When food was presented soon after a reinforced peck, the signal $\mathrm{A}$ overshadowed behaviour. However, when reinforcement was delayed by $3 \mathrm{~s}$, potentiation of instrumental behaviour by the signal was observed. This outcome has also been observed in rats pressing a lever to obtain food pellets as reinforcers. Williams (1999) trained three groups of rats to press a lever for food pellets which came $30 \mathrm{~s}$ after a lever press. One group had no signal between a lever press and food. A second group experienced a 5-s signal (A) immediately after a lever press, whilst the third group experienced the same signal, but in the $5 \mathrm{~s}$ immediately before the pellet was delivered. Relative to the group that experienced no signal between lever press and reinforcement, the group that experienced the 5-s signal immediately before the pellet showed less lever press behaviour (overshadowing). However, the group that experienced the signal immediately after the lever press showed facilitated learning. Thus, these examples show similar interactions between trace conditioning and environmental signals, but in an instrumental scenario.

The effects described in the preceding paragraph are reminiscent of the "gap-filling" effect, which is the observation that when trace conditioning procedures are used, a stimulus filling the "trace interval" between X (or R) and O will overcome the effect of the trace (Kamin, 1965). These results have been observed in rats using Pavlovian aversive conditioning following overshadowing (Pearce, Nicholas \& Dickinson, 1981), pigeon autoshaping (Rescorla, 1982), the rabbit nictitating membrane response (Kehoe, Gibbs, Garcia, \& Gormezano, 1979) and in humans as well (Reed, 1999; Shanks, 1989). Yet another phenomenon that relates to the above mentioned is "marking", a similar attenuation of trace conditioning deficits observed when a salient, albeit brief stimulus, is presented immediately after the response (Lieberman, Mclntosh, \& Thomas, 1979). 
Taken together, it appears that cue competition phenomena occur most readily when reinforcement is presented immediately after $\mathrm{AX}$ compound presentation, and introducing a delay between $A X$ and $O$ leads to no interaction, and sometimes facilitation. Although potentiation has sometimes been documented in the absence of trace conditioning (e.g., Batsell et al., 2012; Exp 3a), potentiation after trace conditioning has been documented in both appetitively and aversively motivated tasks, using rats, pigeons, and humans as subjects. These results are notable because it was cue competition phenomena such as blocking which led researchers to abandon contiguity as a mechanism for learning. But as it turns out, changes in contiguity can have drastic effects on cue competition phenomena, determining whether competition or facilitation are to be observed across different tasks and species.

\section{Other variables}

There is evidence that variables such as stimulus salience, number of trials, or timing of presentation (sequential vs simultaneous) can also influence whether cue competition, no interaction, or cue facilitation are to be observed. In a systematic series of experiments, Bouton and colleagues (Bouton, Jones, McPhillips, \& Swartzentruber, 1986; Bouton, Dunlap \& Swartzentruber, 1987) manipulated the salience of target $(X)$ and interacting $(A)$ cues in flavour aversion learning, and found that potentiation is most apt to occur when the target stimulus $X$ is weakly conditionable. However, overshadowing is also strongest when the overshadowing cue $(A)$ is more salient than the overshadowed cue (X; Mackintosh, 1976), and in humans, increasing the salience of the blocked cue (X) has either resulted in less blocking (Denton \& Kruschke, 2006) or more blocking (Le Pelley, Beesley, \& Griffiths, 2014), and a recent report in category learning found facilitated learning of features by a salient feature, a result in line with potentiation rather than overshadowing (Murphy \& Dunsmoor, 2017). Overall, salience does not seem to be a variable that allows us to predict whether competition between stimuli, or facilitation, is to be observed in any orderly way.

The number of training trials is another variable that has been tested to see whether it determines competition or facilitation. Early investigations into overshadowing assessed whether 
overshadowing occurs after only one AX-O training trial, because some theories predict that it should only occur after the second conditioning trial (Mackintosh, 1975; Pearce \& Hall, 1980; Rescorla \& Wagner, 1972). The evidence suggests that overshadowing can be observed with one trial, although this observation depends on the overshadowing stimulus being of high salience (Mackintosh, \& Reese, 1979). Blocking is an interesting example, as it distinguishes between US processing (i.e., Rescorla \& Wagner, 1972) and attentional theories of learning (Mackintosh, 1975; Pearce \& Hall, 1980), because attentional theories predict that blocking should only be observed after two Phase 2 (AX) conditioning trials. Here, as with salience, the literature is mixed. Some have failed to observe blocking with only one Phase 2 training trial (Mackintosh, 1975b; Mackintosh, Dickinson, \& Cotton, 1980) but other have observed blocking with a single compound trial (Balaz, Kasprow, \& Miller, 1982). Azorlosa and Cicala (1988) also compared different amounts of phase 2 (AX-O) training in blocking, by giving 1,10 , or 30 trials to different groups. They found less blocking after 10 or 30 phase 2 ( $A X-$ O) trials (relative to 1 trial), a result clearly problematic for attentional theories. Consistent with a number of theoretical proposals, some studies have found increased blocking with increased training of the blocking stimulus (A-O; Sanderson, Jones, \& Austen, 2016) but other studies have found less blocking (Pineño, Urushihara, Stout, Fuss, \& Miller, 2006). Interestingly, the opposite of blocking, which is augmentation (Batsell \& Batson, 2001), has also been investigated in terms of its dependency on the number of training trials. Good and colleagues (Good, Allswede, Curley, \& Batsell, 2015) used flavour aversion to investigate whether the number of Phase 1 (Exp 1) or Phase 2 (Exp2) trials determined whether blocking or augmentation are to be observed. In Experiment 1, they administered zero, one, two or four Phase 1 trials, and observed that augmentation increased linearly with number of Phase 1 trials. In Experiment 2, they manipulated the number of Phase 2 trials, and also found increased augmentation with larger Phase 2 trials. Overall, it is unclear whether number of trials predicts whether competition or facilitation are to be observed after compound conditioning.

Finally, another variable which has been proposed to account for the divergent results is the timing of $\mathrm{X}$ and $\mathrm{A}$ presentations during training. In flavour aversion experiments, it has been noted that overshadowing and blocking occur when $X$ and $A$ are presented sequentially before $O$, presumably 
Competition and Facilitation 18

because the closer temporal contiguity of $A$ and $O$ allows $A$ to gain more behavioural control, and hence overshadow or block X (Revusky, 1971). In fact, most studies demonstrating overshadowing or blocking in flavour aversion have used sequential presentations (see Good et al., 2015, for a detailed review). These findings, however, stand in striking contrast with the "gap-filling" experiments described above, and the exact reasons why sequential presentations can lead to enhanced or attenuated learning are unknown. Further research with these questions in mind will have to be conducted to ascertain the source of these discrepancies.

Theoretical interpretations and implications.

In the previous sections, I have reviewed evidence suggesting that variations in three variables (relative duration, contingency, and contiguity) can strongly influence whether cue competition, no interaction, or cue facilitation are to be observed. These variables all relate to regularities in the environment that animals are sensitive to, and which seem to have opposite effects on cue interactions depending on the conditions of training. In elemental training situations $(\mathrm{X}-\mathrm{O})$, increasing the relative stimulus duration, or diminishing contingency or contiguity all decrease behavioural control. When training involves a compound of two cues, or a response and a stimulus, these same variations lead to facilitated behavioural control. At intermediate values (in those few experiments which parametrically manipulated the relevant variables), no interaction between cues has been observed. Perhaps the merit of this exposition is to bring these orderly relationships to the attention of theoreticians, and invite them to address these issues. These variables not only allow us to anticipate whether competition or facilitation is to be observed, they further suggest that under some parametric combinations neither of these effects are to be observed. In fact, when the parameters have been systematically varied, such null outcome has been documented (Batsell et al., 2012 Exps 1a and 1b; Sissons, Urcelay \& Miller, 2009 Exp 3; Urcelay \& Miller, 2009 Exp 1).

There are many theories which can explain cue competition (Mackintosh, 1975; Miller \& Matzel, 1988; Pearce \& Hall, 1980; Pearce, 1987; Pearce \& Mackintosh, 2010; Rescorla \& Wagner, 1972; Wagner, 1981) but they fail to account for potentiation. An extended version of the comparator 
hypothesis (ECH; Denniston, Savastano \& Miller, 2001; Stout \& Miller, 2007) has inspired some of the studies reviewed here, but cannot account for the interaction between compound training and contiguity. The extended comparator hypothesis, which emphasises competition at the time of testing, assumes that when multiple stimuli are trained together $(\mathrm{AX})$, they all enter into associations with the US, as well as become associated between them. As other theories, ECH treats the context similarly to any discrete stimulus, and thus the context can compete for retrieval with the target X-O association. In situations in which there are two discrete cues presented during training (AX), the competition that presumably happens between these two depends in addition on the associative status of the training context, which is high when cues are long, or when contingency is low. That is, with long CSs, short ITIs (see relative stimulus duration above) or when contingency is decreased by presentations of $\mathrm{X}$ or $\mathrm{O}$ alone, the context cancels the potential of the competing stimulus $\mathrm{A}$, and hence $\mathrm{ECH}$ predicts more responding to $\mathrm{X}$ at test (relative to the control condition). This model has inspired many of the studies cited above in which relative stimulus duration and contingency were shown to reverse cue competition into cue facilitation. The formal version of ECH, named SOCR (Stout \& Miller, 2007), also explains another form of facilitation known as higher-order conditioning. Here, AX pairings are preceded or followed by A-O pairings. When subjects are presented with $\mathrm{X}$, the $\mathrm{X}-\mathrm{A}$ and $\mathrm{A}-\mathrm{O}$ chain of associations results in high responding to $\mathrm{X}$ (despite the fact that $\mathrm{X}$ was never paired with O), but only after few trials. In SOCR, this depends on the operator switch, a function that captures whether subjects discriminate between retrieved vs experienced events. With enough training, this function switches from facilitation to competition, resulting in the observation of conditioned inhibition (see Stout, Escobar \& Miller, 2004 for an empirical demonstration). However, SOCR (at least in its pure version) fails to account for the finding that competition reverses into facilitation with variations in contiguity, simply because without $\mathrm{X}-\mathrm{O}$ contiguity, low responding is anticipated to X, and the context cannot "rescue" this decrement. Despite this shortcoming, ECH (and SOCR) has proved its heuristic value by stimulating research which ultimately has been problematic for so-called acquisition focused theories, and indeed has led to revisions of these models (Dickinson \& Burke, 1996; Van Hamme \& Wasserman, 1994). 
Competition and Facilitation 20

Different explanations have been espoused to explain facilitated learning after compound conditioning. I will review two of these, perhaps because they have been successful in stimulating experiments and debates, but it is worth clarifying that these are examples of families of theories. One of them, the within-compound association model, explains potentiation as a form of higher order conditioning. Recall that in the potentiation experiments described above, a low salience stimulus $\mathrm{X}$ is presented together with a more salient stimulus $\mathrm{A}$ and followed by $\mathrm{O}$ (usually after a trace). Because both $\mathrm{X}$ and $\mathrm{A}$ were presented simultaneously, an association between them is formed (the withincompound association; Durlach \& Rescorla, 1980). Because $X$ is of low salience, it becomes weakly associated with $\mathrm{O}$. But the potentiating cue $\mathrm{A}$, because of its higher salience, becomes strongly associated with $\mathrm{O}$. At the time of test, the hypothetical X-A-O chain mediates strong conditioned responding to $X$, because $X$ is associated with $A$, which in turn is associated with $O$. A strong prediction of this model is that, following potentiation training, extinction of $A$ (the potentiating cue) should attenuate responding to $\mathrm{X}$, because after $\mathrm{A}$ alone presentations both, the $\mathrm{X}$ - $\mathrm{A}$ withincompound association, and the association between $\mathrm{A}$ and $\mathrm{O}$ have been extinguished. This prediction has been tested in many experiments that documented potentiation, and has found strong support (Durlach \& Rescorla, 1980; Horne \& Pearce, 2011; Slotnick, Westbrook, \& Darling, 1997).

An alternative explanation of potentiation is based on configural learning of the AX compound. In other words, during initial exposures to the compound, organisms process it as a unit (i.e., a Gestalt) that is more salient than the sum of its elements A and X. It is only after experiencing the elements alone that an animal will discriminate the elements from the compound. This explanation was proposed early on by William James (1890), later by Robinson (1932), and applied to potentiation by Rescorla (1981; also see Kucharski \& Spear, 1985; Trost \& Batsell, 2004; Urcelay \& Miller, 2009). It explains potentiation by positing that during compound conditioning, animals form a unitary representation of the $\mathrm{AX}$ compound, that because of its higher salience becomes associated with $\mathrm{O}$. At test, when $X$ is presented alone, the animal confuses $X$ with the salient $A X$ compound, and hence responds strongly. This explanation is at odds with configural models of learning that assume sharp generalization decrements to explain cue competition phenomena (Pearce, 1987), because the 
assumption here is that there is little generalization decrement between $A X$ and $X$. Of course, this configural account can explain the effect of extinction of $A$ following $A X-O$ training, because with enough experience ( $A$ alone) animals discriminate the elements from the compound, and such misidentification of the element $X$ with the compound $A X$ is less likely to happen. Thus, extinction of the potentiating cue A does not differentiate between these two accounts, nor does the finding of potentiation with simultenaous AX presentations versus sequential (see Urcelay \& Miller, 2009 for alternative strategies). Finally, it may be the case that potentiation and augmentation arise from different mechanisms, for example some have proposed potentiation results from configural encoding, whereas augmentation results from within-compound associations (Trost \& Batsell, 2004).

Despite the success of the within-compound association and configural accounts to explain facilitation, they do not offer a straightforward explanation for cue competition. Some have proposed that within-compound associations attenuate cue competition phenomena, and even sometimes outweigh them, leading to facilitation (Pearce, Nicholas \& Dickinson, 1981; Horne \& Pearce, 2011). However, given that within-compound associations are critical to the observation of some forms of cue competition such as backward blocking (Aitken, Larkin \& Dickinson, 2001), and that some models have assume within-compound associations to be critical for the observation of all forms of cue competition (Miller \& Matzel, 1988), it is not clear how within-compound associations can sometimes lead to competition, and sometimes lead to facilitation. As mentioned above, configural accounts of cue competition assume large generalization decrements to explain cue competition (Pearce, 1987), but in this way they fail to explain facilitation (also see Trost \& Batsell, 2004; for a tentative account of facilitation that assumes configural processing and within-compound associations acting in concert).

To explain both cue competition and facilitation, some have appealed to "hybrid" explanations, whereby elemental processing underlies cue competition phenomena, and configural processing underlies facilitation (Melchers, Shanks and Lachnit, 2008; Urcelay \& Miller, 2009). The main assumption of this "flexible processing" approach is that humans and other animals are capable of processing stimuli in an elemental or configural way, and that variables such as task demands, prior experience, experimental instructions, and stimulus properties can all affect whether elemental or 
configural processing is to be in operation. Although some of these variables apply predominantly to human experiments (task demands, experimental instructions), Urcelay and Miller (2009) found strong support for this flexible approach by showing that prior experience with a different set of stimuli could affect both facilitation and competition between $\mathrm{AX}$. That is, prior elemental training (relative validity; $\mathrm{BY}-\mathrm{O} / \mathrm{CY}-\mathrm{NoO}$ ) eliminated potentiation to $\mathrm{X}$ after $\mathrm{AX}---\mathrm{O}$ training using trace conditioning (Exp 3), and prior configural training (negative patterning; Y-O/B-O/YB-NoO) reduced overshadowing of $\mathrm{X}$ after AX-O training using delay conditioning (Exp 4). These results support the notion of representational flexibility in nonhuman animals, and suggest that competition results from elemental processing, and facilitation from configural processing. Whether elemental and configural processing also underlie competition and facilitation with variations in relative stimulus duration and contingency is an open question for future research.

In addition to these theoretical considerations, there is perhaps a more prosaic explanation for the observation of competition and facilitation with variations in relative stimulus duration, contingency and contiguity. Recall that configural models that explain cue competition assume large generalization decrements to explain these (Pearce, 1987). However, configural explanations of facilitation propose that animals "confuse" the test stimulus X with the AX compound in order to explain potentiation. In other words, the latter explanation assumes little if any generalization decrement (Rescorla, 1981). It is possible that variations in relative duration, contingency and contiguity have an effect on generalization decrement from $\mathrm{AX}$ (configured) compound training to $\mathrm{X}$ at test, and this explains whether competition or facilitation are to be observed after compound training. Using delay conditioning procedures, sharp generalization gradients are usually observed, but as noted by Pavlov (1927, p113) trace conditioning may result in "permanent and universal generalization" a finding that has been confirmed by others more recently (see Honey \& Hall, 1993 for a similar observation). Generalization gradients also widen as a function of decreased contingency. This was observed by Humphreys (1939; also see Mackintosh 1974, Chapter 9), who measured generalization gradients to variations of a stimulus that was reinforced either $100 \%$, or $50 \%$. He found a negatively accelerated gradient with $100 \%$ reinforcement, but almost no generalization decrement to the variations of a 
Competition and Facilitation 23

stimulus reinforced $50 \%$. Whether generalization gradients vary as a function of relative stimulus duration is a question worth investigating in the future. Perhaps manipulating these three variables introduces "ambiguity" or "uncertainty", which then leads to flattened generalization gradients from compound training to test, thus resulting in facilitation after compound training.

Whatever the merits of these theoretical speculations, the implications of variations in relative duration, contingency, and contiguity for spatial learning are noteworthy. Many investigators have argued that associative principles of learning apply to spatial learning scenarios, and this contention has received empirical support by the observation of cue competition phenomena (overshadowing and blocking) in the spatial domain in rats and humans (Prados, 2011; Rodrigo, Chamizo, McLaren \& Mackintosh, 1997; Sanchez-Moreno, Rodrigo, Chamizo, \& Mackintosh, 1999). These results provide strong support for an associative explanation of spatial learning. However, other studies have failed to obtain such cue competition phenomena in the spatial domain (Doeller \& Burgess, 2008), and some researchers have concluded that the lack of cue competition supports the idea that spatial learning requires a specialized "geometric module" (O’Keefe \& Nadel, 1978). Some studies have found both competition and facilitation in separate spatial learning experiments (Horne \& Pearce, 2011; Pearce, Graham, Good, Jones, \& McGregor, 2006), but the reasons for these discrepant findings are not clear. Spatial learning involves learning about spatially discontiguous events such as geometrical boundaries, landmarks, and goals, and in many circumstances cues are partially reinforced. Thus, the three variables outlined here could in principle provide a fruitful avenue for investigating the reasons for the disparate outcomes in spatial learning reported in the literature. For example, Goodyear and Kamil (2004) assessed the effects of goal-landmark (spatial) distance on overshadowing in nutcrackers. They found overshadowing but only to the closest landmark, as the landmark-goal distance increased, overshadowing waned, a result entirely consistent with the present analysis. In addition, a model which relies on associative rules to explain spatial learning appeals to a "feature enhancement" mechanism to account for facilitation in spatial learning, and this mechanism only works with low contingency events such as geometry (e.g., in a rectangular enclosure, geometry leads to reward half of the time; Miller \& Shettleworth, 2007). 
Finally, the present analysis has implications for functional approaches to learning. The observation of cue competition has led some to suggest that cue competition occurs because animals have to limit how much information to process, and this is adaptive. For example, Blaisdell (2003, p 146) has argued that "it is adaptive for a creature to respond selectively to environmental input". Whilst I do not wish to strongly dispute this statement, I note that similar functional explanations have been put forward to explain cue facilitation. That is, Garcia and colleagues (Palmerino, Rusiniak, \& Garcia, 1980) observed potentiation (rather than overshadowing) between odors and tastes and suggested that this was a modality specific effect, which occurred due to the importance of the taste system to survival (Garcia, Lasiter, Bermudez-Rattoni, \& Deems, 1985). In other words, they appealed to a functional argument to explain why potentiation rather than overshadowing was observed in flavour aversion. Taken together, we are left with a functional explanation for cue competition, and different one for facilitation. The current analysis suggests that both competition and facilitation are endpoints of a continuum and hence we shall be very cautious of applying a functional explanation for each, and particularly doing so in a post hoc manner. Rather, we should see learning as constrained by a number of variables that relate to the physical regularities (spatio-temporal) of the environment - the resultant can be competition, no interaction, or facilitation. This simplifies the analysis by proposing that multiple outcomes are possible under specific parametric variations guided by the three variables highlighted here. Although there are results which do not necessarily conform to the current empirical generalization, and the evidence supporting the current analysis has been obtained predominantly using overshadowing preparations, these variables provide a starting point as candidates that may explain different outcomes after compound training. Because most (but not all) of the examples provided have been tested in overshadowing, it is a question for future research to determine whether the same principles apply to other cue competition preparations.

In summary, the current commentary highlights three variables that, when experimentally manipulated, have led to competition, no interaction, or facilitation. These findings have been observed across different preparations, sensory modalities, and species. In light of this analysis, failures to observe cue competition (like instances reported by Maes et al., 2016) should perhaps not 
Competition and Facilitation 25

be considered exceptional. It is perhaps time to begin to consider three different outcomes as resulting from cue interactions (competition, no interaction, facilitation), and develop theories that account for what so far have been considered as disparate (domain specific) findings. The proposed approach assumes domain general principles that are constrained by the regularities of the environment, and are applicable to learning situations irrespective of sensory modality or cognitive system. 


\section{References}

Acebes, F., Solar, P., Carnero, S., \& Loy, I. (2009). Blocking of conditioning of tentacle lowering in the snail (Helix aspersa). Quarterly Journal of Experimental Psychology, 62(7), 1315-1327.

Aitken, M. F., Larkin, M. W., \& Dickinson, A. (2001). Re-examination of the role of within-compound associations in the retrospective revaluation of causal judgements. The Quarterly Journal of Experimental Psychology B, 54B(1), 27-51. doi:10.1080/02724990042000029

Allan, L.G. (1980). A note on measurement of contingency between two binary variables in judgment tasks. Bulletin of the Psychonomic Society, 15, 147-149.

Azorlosa, J.L., \& Cicala, G.A. (1988). Increased conditioning in rats to a blocked CS after the first compound trial. Bulletin of the Psychonomic Society, 26, 254257.

Balaz, M. A., Kasprow, W. J., \& Miller, R. R. (1982). Blocking with a single compound trial. Animal Learning \& Behavior, 10(3), 271-276.

Batsell, W. R., \& Batson, J. D. (1999). Augmentation of taste conditioning by a preconditioned odor. Journal of Experimental Psychology: Animal Behavior Processes, 25(3), 374-388.

Batsell, W. R., Wakefield, E., Ulrey, L. A., Reimink, K., Rowe, S. L., \& Dexheimer, S. (2012). CS-US interval determines the transition from overshadowing to potentiation with flavor compounds. Learning \& Behavior, 40(2), 180-194.

Beesley, T., \& Shanks, D. R. (2012). Investigating cue competition in contextual cuing of visual search. Journal of Experimental Psychology: Learning, Memory, and Cognition, 38(3), 709-725. doi:10.1037/a0024885

Blaisdell, A. P. (2003). The S-R information stream: Where's the filter? Integrative Physiological \& Behavioral Science, 38(2), 146-165.

Blaisdell, A. P., Bristol, A. S., Gunther, L. M., \& Miller, R. R. (1998). Overshadowing and latent inhibition counteract each other: Support for the comparator hypothesis. Journal of Experimental Psychology: Animal Behavior Processes, 24(3), 335-351. 
Competition and Facilitation 27

Boakes, R. A., \& Costa, D. J. (2014). Temporal contiguity in associative learning: Interference and decay from an historical perspective. Journal of Experimental Psychology: Animal Learning And Cognition, 40(4), 381-400.

Bouton, M. E., Dunlap, C. M., \& Swartzentruber, D. (1987). Potentiation of taste by another taste during compound aversion learning. Animal Learning \& Behavior, 15(4), 433-438. doi:10.3758/BF03205053

Bouton, M.E., Jones, D.L., McPhillips, S.A., \& Swartzentruber, D. (1986). Potentiation and overshadowing in odor-aversion learning: Role of method of odor presentation, the distalproximal cue distinction, and the conditionability of odor. Learning and Motivation, 17, 115-138. Brogden, W.J. (1939). Sensory pre conditioning. Journal of Experimental Psychology, 25, 323332. Couvillon, P. A., \& Bitterman, M. E. (1989). Reciprocal overshadowing in the discrimination of colorodor compounds by honeybees: Further tests of a continuity model. Animal Learning \& Behavior, 17(2), 213-222.

Cunha, M. J., Forehand, M. R., \& Angle, J. W. (2015). Riding coattails: When co-branding helps versus hurts less-known brands. Journal of Consumer Research, 41(5), 1284-1300.

Denniston, J.C., Savastano, H.I., \& Miller, R.R. (2001). The extended comparator hypothesis: Learning by contiguity, responding by relative strength. In R.R. Mowrer \& S.B. Klein (Eds.), Handbook of contemporary learning theories (pp. 65-117). Hillsdale, NJ: Erlbaum.

Denton, S. E., \& Kruschke, J. K. (2006). Attention and salience in associative blocking. Learning \& Behavior, 34(3), 285-304.

Dickinson, A., \& Burke, J. (1996). Within-compound associations mediate the retrospective revaluation of causality judgements. The Quarterly Journal of Experimental Psychology B, 49B (1), 60-80. doi:10.1080/713932614

Dickinson, A., Shanks, D., \& Evenden, J. (1984). Judgement of act-outcome contingency: The role of selective attribution. The Quarterly Journal of Experimental Psychology A, 36(1-A), 29-50. 
Competition and Facilitation 28

Doeller, C. F., \& Burgess, N. (2008). Distinct error-correcting and incidental learning of location relative to landmarks and boundaries. PNAS Proceedings of the National Academy of Sciences of the United States of America, 105(15), 5909-5914.

Durlach, P. J., \& Rescorla, R. A. (1980). Potentiation rather than overshadowing in flavor-aversion learning: An analysis in terms of within-compound associations. Journal of Experimental Psychology: Animal Behavior Processes, 6(2), 175-187. doi:10.1037/0097-7403.6.2.175

Ferster, C. B., \& Skinner, B. F. (1957). Schedules of reinforcement. East Norwalk, CT, US: AppletonCentury-Crofts. doi:10.1037/10627-000

Garcia, J., Ervin, F.R., \& Koelling, R.A. (1966). Learning with long delay of reinforcement. Psychonomic Science, 5, 121122.

Garcia, J., Lasiter, P. S., Bermudez-Rattoni, E, \& Deems, D. A. (1985). A general theory of aversion learning. In N. S. Braveman \& P. Bronstein (Eds.), Annals of the New York Academy of Sciences: Vol. 443. Experimental assessments and clinical applications of conditioned food aversions (pp. 8-21). New York: New York Academy of Sciences.

Gibbon, J., Baldock, M. D., Locurto, C., Gold, L., \& Terrace, H. S. (1977). Trial and intertrial durations in autoshaping. Journal of Experimental Psychology: Animal Behavior Processes, 3, 264-284.

Good, I., Allswede, D., Curley, K., \& Batsell, W. J. (2015). Increasing trial number produces augmentation, not blocking, in flavor-aversion conditioning. Learning and Motivation, 49, 38-50. doi:10.1016/j.Imot.2015.01.002

Goodyear, A. J., \& Kamil, A. C. (2004). Clark's Nutcrackers (Nucifraga columbiana) and the Effects of Goal--Landmark Distance on Overshadowing. Journal of Comparative Psychology, 118(3), 258264. doi:10.1037/0735-7036.118.3.258

Honey, R. C., \& Hall, G. (1992). CS memory after trace conditioning. Learning and Motivation, 23(2), 145-155. doi:10.1016/0023-9690(92)90014-D

Horne, M. R., \& Pearce, J. M. (2011). Potentiation and overshadowing between landmarks and environmental geometric cues. Learning \& Behavior, 39(4), 371-382. doi:10.3758/s13420-0110032-8 
Competition and Facilitation 29

Humphreys, L. G. (1939). Generalization as a function of method of reinforcement. Journal of Experimental Psychology, 25(4), 361-372. doi:10.1037/h0057941

James, W. (1890). The principles of psychology. NY, US: Henry Holt and Company. doi:10.1037/11059-000

Kamin, L. J. (1961). Trace conditioning of the conditioned emotional response. Journal of Comparative and Physiological Psychology, 54(2), 149-153.

Kamin, L. J. (1965). Temporal and intensity characteristics of the conditioned stimulus. In W. F. Prokasy (Ed.) Classical Conditioning: a Symposium. New York: Appleton-Century-Crofts. Kamin, L.J. (1968). 'Attention like" processes in classical conditioning. In M.R. Jones (Ed.), Miami symposium on the prediction of behavior: Aversive stimulation (pp. 9 31). Miami, FL: University of Miami Press.

Kehoe, E. J., Gibbs, C. M., Garcia, E., \& Gormezano, I. (1979). Associative transfer and stimulus selection in classical conditioning of the rabbit's nictitating membrane response to serial compound CSs. Journal of Experimental Psychology: Animal Behavior Processes, 5(1), 1-18. doi:10.1037/0097-7403.5.1.1

Kucharski, D., \& Spear, N. E. (1985). Potentiation and overshadowing in preweanling and adult rats. Journal of Experimental Psychology: Animal Behavior Processes, 11(1), 15-34. doi:10.1037/0097-7403.11.1.15

Le Pelley, M. E., Beesley, T., \& Griffiths, O. (2014). Relative salience versus relative validity: Cue salience influences blocking in human associative learning. Journal of Experimental Psychology: Animal Learning and Cognition, 40(1), 116-132.

Leyland, C.M., \& Mackintosh, N.J. (1978). Blocking of first and second order autoshaping in pigeons. Animal Learning \& Behavior, 6, 391394.

Lieberman, D. A., Mclntosh, D. C., \& Thomas, G. V. (1979). Learning when reward is delayed: A marking hypothesis. Journal of Experimental Psychology: Animal Behavior Processes, 5(3), 224-242. doi:10.1037/0097-7403.5.3.224 
Competition and Facilitation 30

Lipatova, O., Wheeler, D. S., Vadillo, M. A., \& Miller, R. R. (2006). Recency-to-primacy shift in cue competition. Journal Of Experimental Psychology: Animal Behavior Processes, 32(4), 396-406. doi:10.1037/0097-7403.32.4.396

Loy, I., \& Hall, G. (2002). Taste aversion after ingestion of lithium chloride: An associative analysis. The Quarterly Journal of Experimental Psychology B, 55B(4), 365-380.

Lubow, R.E., \& Moore, A.U. (1959). Latent inhibition: The effect of nonreinforced preexposure to the conditioned stimulus. Journal of Comparative and Physiological Psychology, 52, 415419.

Mackintosh, N.J. (1974). The psychology of animal learning. London: Academic Press.

Mackintosh, N.J. (1975). A theory of attention: Variations in the associability of stimuli with reinforcement. Psychological Review, 82, 276298.

Mackintosh, N. J. (1975b). Blocking of conditioned suppression: Role of the first compound trial. Journal of Experimental Psychology: Animal Behavior Processes, 1(4), 335-345. doi:10.1037/0097-7403.1.4.335

Mackintosh, N. J. (1976). Overshadowing and stimulus intensity. Animal Learning \& Behavior, 4(2), 186-192.

Mackintosh, N. J., Dickinson, A., \& Cotton, M. M. (1980). Surprise and blocking: Effects of the number of compound trials. Animal Learning \& Behavior, 8(3), 387-391. doi:10.3758/BF03199622

Mackintosh, N. J., \& Reese, B. (1979). One-trial overshadowing. The Quarterly Journal of Experimental Psychology, 31(3), 519-526. doi:10.1080/14640747908400743

Maes, E., Boddez, Y., Alfei, J. M., Krypotos, A., D’Hooge, R., De Houwer, J., \& Beckers, T. (2016). The elusive nature of the blocking effect: 15 failures to replicate. Journal of Experimental Psychology: General, 145(9), e49-e71.

Maier, S. F., Jackson, R. L., \& Tomie, A. (1987). Potentiation, overshadowing, and prior exposure to inescapable shock. Journal of Experimental Psychology: Animal Behavior Processes, 13(3), $260-270$. 
Competition and Facilitation 31

Melchers, K. G., Shanks, D. R., \& Lachnit, H. (2008). Stimulus coding in human associative learning:

Flexible representations of parts and wholes. Behavioural Processes, 77(3), 413-427.

doi:10.1016/j.beproc.2007.09.013

Miller, R.R., \& Matzel, L.D. (1988). The comparator hypothesis: A response rule for the expression of associations. In G.H. Bower (Ed.), The psychology of learning and motivation, Vol. 22 (pp. 51 92). San Diego, CA: Academic Press.

Miller, N. Y., \& Shettleworth, S. J. (2007). Learning about environmental geometry: An associative model. Journal of Experimental Psychology: Animal Behavior Processes, 33(3), 191-212.

Murphy, G. L., \& Dunsmoor, J. E. (2017). Do Salient Features Overshadow Learning of Other Features in Category Learning? Journal of Experimental Psychology: Animal Learning and Cognition. doi:10.1037/xan0000139

Nagaishi, T., \& Nakajima, S. (2008). Further evidence for the summation of latent inhibition and overshadowing in rats' conditioned taste aversion. Learning and Motivation, 39(3), 221-242.

Nakajima, S., \& Nagaishi, T. (2005). Summation of latent inhibition and overshadowing in a generalized bait shyness paradigm of rats. Behavioural Processes, 69(3), 369-377.

Neely, J. H., \& Wagner, A. R. (1974). Attenuation of blocking with shifts in reward: The involvement of schedule-generated contextual cues. Journal of Experimental Psychology, 102(5), 751-763. doi: $10.1037 / \mathrm{h} 0036410$

O’Keefe, J., \& Nadel, L. (1978). The Hippocampus as a Cognitive Map. Oxford University Press. Palmerino, C.C., Rusiniak, D.W., \& Garcia, J. (1980). Flavor illness aversions: The peculiar roles of odor and taste in memory for poisons. Science, 208, 753755.

Pavlov, I.P. (1927). Conditioned reflexes. (G.V. Anrep, Ed. \& Trans.) London: Oxford University Press.

Pearce, J. M. (1987). A model for stimulus generalization in Pavlovian conditioning. Psychological Review, 94(1), 61-73. doi:10.1037/0033-295X.94.1.61 
Pearce, J. M., Graham, M., Good, M. A., Jones, P. M., \& McGregor, A. (2006). Potentiation, overshadowing, and blocking of spatial learning based on the shape of the environment. Journal of Experimental Psychology: Animal Behavior Processes, 32(3), 201-214.

Pearce, J.M., \& Hall, G. (1980). A model for Pavlovian learning: Variations in the effectiveness of conditioned but not unconditioned stimuli. Psychological Review, 82, 532-552.

Pearce, J. M. \& Mackintosh, N. J. (2010). Two theories of attention: A review and a possible integration. In C. Mitchell and M.E. LePelley (Eds.) Attention and Learning, (pp. 11-39). Oxford: Oxford University Press.

Pearce, J. M., Nicholas, D. J., \& Dickinson, A. (1981). The potentiation effect during serial conditioning. The Quarterly Journal of Experimental Psychology B: Comparative and Physiological Psychology, 33B(3), 159-179. doi:10.1080/14640748108400820

Pezze, M. A., Marshall, H. J., \& Cassaday, H. J. (2016). Potentiation rather than distraction in a trace fear conditioning procedure. Behavioural Processes, 12, 841-46. doi:10.1016/j.beproc.2016.04.003

Pineño, O., Urushihara, K., Stout, S., Fuss, J., \& Miller, R. R. (2006). When more is less: Extending training of the blocking association following compound training attenuates the blocking effect. Learning \& Behavior, 34(1), 21-36.

Prados, J. (2011). Blocking and overshadowing in human geometry learning. Journal of Experimental Psychology: Animal Behavior Processes, 37(1), 121-126.

Prados, J., Alvarez, B., Howarth, J., Stewart, K., Gibson, C. L., Hutchinson, C. V., \& ... Davidson, C. (2013). Cue competition effects in the planarian. Animal Cognition, 16(2), 177-186.

Reed, P. (1999). Role of a stimulus filling an action-outcome delay in human judgments of causal effectiveness. Journal of Experimental Psychology: Animal Behavior Processes, 25(1), 92-102. doi:10.1037/0097-7403.25.1.92

Reed, P., Schachtman, T. R., \& Hall, G. (1988). Overshadowing and potentiation of instrumental responding in rats as a function of the schedule of reinforcement. Learning and Motivation, 19(1), 13-30. doi:10.1016/0023-9690(88)90023-9 
Competition and Facilitation 33

Rescorla, R.A. (1968). Probability of shock in the presence and absence of CS in fear conditioning. Journal of Comparative and Physiological Psychology, 66, 1-5.

Rescorla, R.A. (1970). Reduction in the effectiveness of reinforcement after prior excitatory conditioning. Learning and Motivation, 1, 372-381.

Rescorla, R.A. (1981). Simultaneous associations. In P. Harzem and M.D. Zeiler (Eds.), Predictability, correlation, and contiguity (pp. 47 80). New York: Wiley.

Rescorla, R. A. (1982). Effect of a stimulus intervening between CS and US in autoshaping. Journal of Experimental Psychology: Animal Behavior Processes, 8(2), 131-141. doi:10.1037/00977403.8.2.131

Rescorla, R. A. (1988). Behavioral studies of Pavlovian conditioning. Annual Review of Neuroscience, 11, 329-352.

Rescorla, R.A., \& Wagner, A.R. (1972). A theory of Pavlovian conditioning: Variations in the effectiveness of reinforcement and nonreinforcement. In A.H. Black \& W.F. Prokasy (Eds.), Classical conditioning II: Current research and theory (pp. 64 99). New York: Appleton Century Crofts.

Revusky, S.H. (1971). The role of interference in association over a delay. In W.K. Honig \& P.H.R. James (Eds.), Animal memory (pp. 155 213). New York: Academic Press.

Robinson, E. S. (1932). Association theory today. London, England: Century/Random House UK. Roberts, W. H. (1930). The effect of delayed feeding on white rats in a problem cage. The Pedagogical Seminary and Journal of Genetic Psychology, 37, 35-58.

Rodrigo, T., Chamizo, V. D., McLaren, I. L., \& Mackintosh, N. J. (1997). Blocking in the spatial domain. Journal of Experimental Psychology: Animal Behavior Processes, 23(1), 110-118.

Sánchez-Moreno, J., Rodrigo, T., Chamizo, V. D., \& Mackintosh, N. J. (1999). Overshadowing in the spatial domain. Animal Learning \& Behavior, 27(4), 391-398.

Sanderson, D. J., Jones, W. S., \& Austen, J. M. (2016). The effect of the amount of blocking cue training on blocking of appetitive conditioning in mice. Behavioural Processes, 122, 36-42. 
Competition and Facilitation 34

Schachtman, T. R., Reed, P., \& Hall, G. (1987). Attenuation and enhancement of instrumental responding by signals for reinforcement on a variable interval schedule. Journal of Experimental Psychology: Animal Behavior Processes, 13(3), 271-279.

Shanks, D.R., (1987). Acquisition functions in contingency judgment. Learning and Motivation, 18, 147-166.

Shanks, D. R. (1989). Selectional processes in causality judgment. Memory \& Cognition, 17(1), $27-34$. doi:10.3758/BF03199554

Shanks, D.R., \& Dickinson, A. (1991). Instrumental judgement and performance under variations in action-outcome contingency and contiguity. Memory and Cognition, 19, 353-360.

Sissons, H. T., \& Miller, R. R. (2009). Overexpectation and trial massing. Journal of Experimental Psychology: Animal Behavior Processes, 35(2), 186-196.

Sissons, H. T., Urcelay, G. P., \& Miller, R. R. (2009). Overshadowing and CS duration: Counteraction and a reexamination of the role of within-compound associations in cue competition. Learning \& Behavior, 37(3), 254-268.

Slotnick, B. M., Westbrook, F., \& Darling, F. C. (1997). What the rat's nose tells the rat's mouth: Long delay aversion conditioning with aqueous odors and potentiation of taste by odors. Animal Learning \& Behavior, 25(3), 357-369. doi:10.3758/BF03199093

Stout, S. C., Chang, R., \& Miller, R. R. (2003). Trial spacing is a determinant of cue interaction. Journal of Experimental Psychology: Animal Behavior Processes, 29(1), 23-38.

Stout, S., Escobar, M., \& Miller, R. R. (2004). Trial number and compound stimuli temporal relationship as joint determinants of second-order conditioning and conditioned inhibition. Learning \& Behavior, 32(2), 230-239. doi:10.3758/BF03196024

Stout, S. C., \& Miller, R. R. (2007). Sometimes-competing retrieval (SOCR): A formalization of the comparator hypothesis. Psychological Review, 114(3), 759-783.

Trost, C. A., \& Batsell, W. J. (2004). Taste + odor interactions in compound aversion conditioning. Learning \& Behavior, 32(4), 440-453. doi:10.3758/BF03196040 
Competition and Facilitation 35

Urcelay, G. P., \& Miller, R. R. (2006). Counteraction between overshadowing and degraded contingency treatments: Support for the extended comparator hypothesis. Journal of Experimental Psychology: Animal Behavior Processes, 32(1), 21-32.

Urcelay, G. P., \& Miller, R. R. (2009). Potentiation and overshadowing in Pavlovian fear conditioning. Journal of Experimental Psychology: Animal Behavior Processes, 35(3), 340-356.

Urushihara, K., \& Miller, R. R. (2006). Overshadowing and the outcome-alone exposure effect counteract each other. Journal of Experimental Psychology: Animal Behavior Processes, 32(3), 253-270.

Urushihara, K., \& Miller, R. R. (2007). CS-duration and partial-reinforcement effects counteract overshadowing in select situations. Learning \& Behavior, 35(4), 201-213.

Urushihara, K., Stout, S. C., \& Miller, R. R. (2004). The basic laws of conditioning differ for elemental cues and cues trained in compound. Psychological Science, 15(4), 268-271.

Vadillo, M. A., Castro, L., Matute, H., \& Wasserman, E. A. (2008). Backward blocking: The role of within-compound associations and interference between cues trained apart. The Quarterly Journal of Experimental Psychology, 61(2), 185-193. doi:10.1080/17470210701557464

Van Hamme, L. J., \& Wasserman, E. A. (1994). Cue competition in causality judgments: The role of nonpresentation of compound stimulus elements. Learning and Motivation, 25(2), 127-151. doi:10.1006/Imot.1994.1008

Waelti, P., Dickinson, A., \& Schultz, W. (2001). Dopamine responses comply with basic assumptions of formal learning theory. Nature, 412(6842), 43-48.

Wagner, A.R. (1981). SOP: A model of automatic memory processing in animal behavior. In N.E. Spear \& R.R. Miller (Eds.), Information processing in animals: Memory mechanisms (pp. 5-47). Hillsdale, NJ: Erlbaum.

Wagner, A.R., Logan, F.A., Haberlandt, K., \& Price, T. (1968). Stimulus selection and a "modified continuity theory." Journal of Experimental Psychology, 76, 171180. 
Wagner, A. R., Siegel, S., Thomas, E., \& Ellison, G. D. (1964). Reinforcement history and the extinction of a conditioned salivary response. Journal of Comparative \& Physiological Psychology, 58, 354-358.

Westbrook, R. F., Homewood, J., Horn, K., \& Clarke, J. C. (1983). Flavour-odour compound conditioning: Odour-potentiation and flavour-attenuation. The Quarterly Journal of Experimental Psychology B, 35(B-1), 13-33.

Wheeler, D. S., Stout, S. C., \& Miller, R. R. (2004). Interaction of retention interval with CSpreexposure and extinction treatments: Symmetry with respect to primacy. Learning \& Behavior, 32(3), 335-347. doi:10.3758/BF03196032

Williams, B. A. (1999). Associative competition in operant conditioning: Blocking the responsereinforcer association. Psychonomic Bulletin \& Review, 6(4), 618-623. 


\section{Author Notes}

The author would like to thank Carlo De Lillo, José Prados, and 4 reviewers for constructive comments and suggestions on this manuscript. 


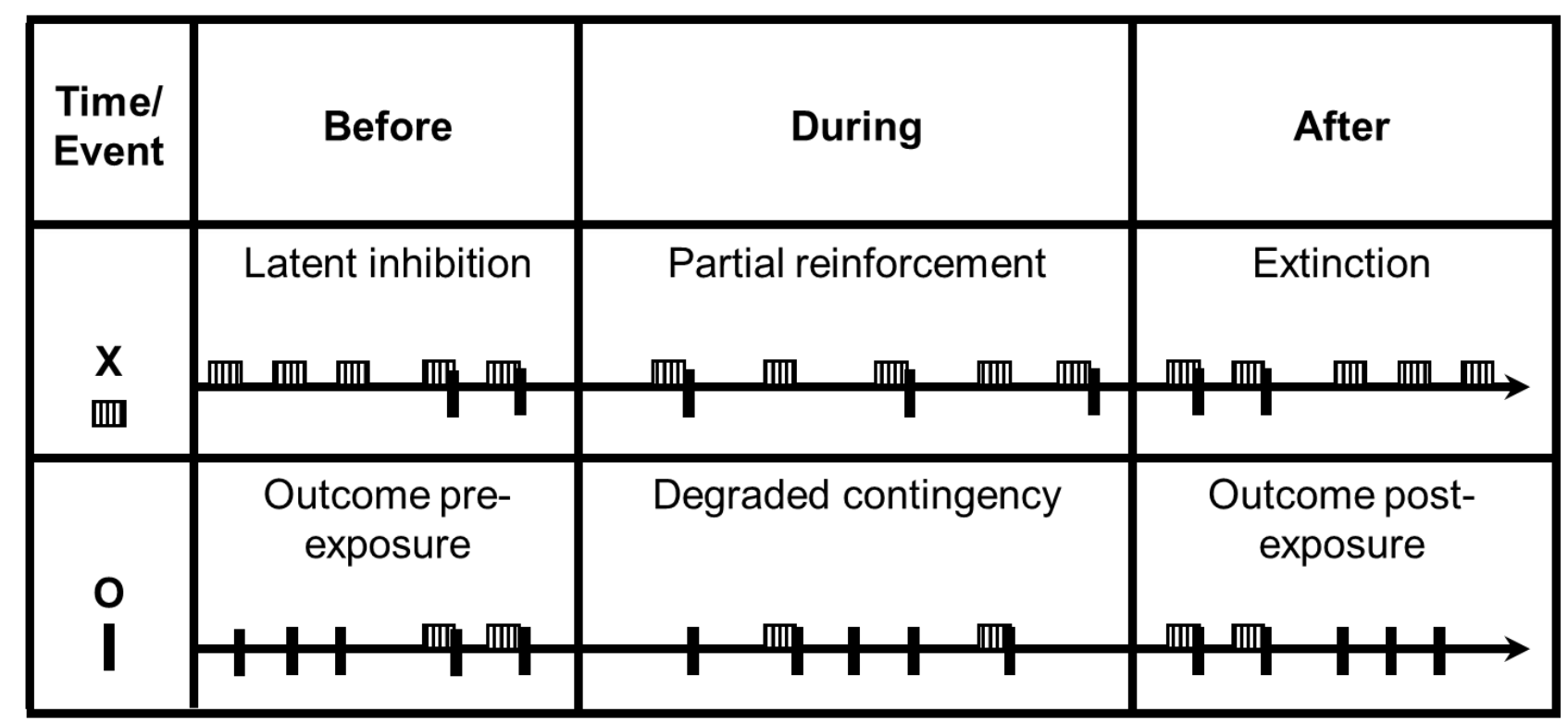

Figure 1. Diagram depicting six different ways in which the objective contingency between $\mathrm{X}$ and $\mathrm{O}$ can be degraded. That is, by presenting either $\mathrm{X}$ or $\mathrm{O}$ alone, and doing this before, during, or after $\mathrm{X}$ O pairings, the objective contingency can be degraded. Labels refer to commonly used names for these procedures. 